\title{
Layer Charge Effects on Adsorption and Diffusion of Water and Ions in Interlayers and on External Surfaces of Montmorillonite
}

\author{
Yafan Yang, Arun Kumar Narayanan Nair* and Shuyu Sun
} Physical Science and Engineering Division (PSE), Computational Transport Phenomena Laboratory, King Abdullah University of Science and Technology (KAUST), Thuwal, 23955-6900, Saudi Arabia.

November 18, 2019

\footnotetext{
*To whom correspondence should be addressed, email: arun.narayanannair@kaust.edu.sa
} 


\begin{abstract}
Molecular simulations using classical force fields were performed to study the adsorption and diffusion properties of water and ions in the high-charge (Arizonatype) montmorillonite clays with varying relative humidity $(\mathrm{RH})$ at $298.15 \mathrm{~K}$. The simulation results of basal distances derived from swelling free energy curves and of water uptake are in good agreement with experiments. Overall, the simulated self-diffusion coefficients of the interlayer species are in reasonable agreement with experiments and lower than those estimated for the external surfaces. Influence of the magnitude of the layer charge was studied by comparing these simulation results with those obtained for the low-charge (Wyoming-type) montmorillonite clays. Most importantly, these comparisons confirm the experimental finding that the high-charge clay generally shifts swelling transitions toward lower $\mathrm{RH}$ values. Therefore, the adsorption and dynamics of water and ions are significantly different in the low- and high-charge clays near the transition $\mathrm{RH}$ values. We find that the amount of water in an interlayer hydration state is mostly independent of the layer charge, probably due to steric reasons. In contrast, the externally adsorbed water content increases with increasing layer charge. Furthermore, the mobility of water and ions is generally lower in the high-charge montmorillonite than in the corresponding low-charge system. However, mobility of cations in the mesopores of high-charge montmorillonite is typically higher than that of the corresponding low-charge system which might be attributed to the presence of the tetrahedral substitutions in the later case.
\end{abstract}

KEYWORDS: Montmorillonite, adsorption, diffusion, molecular dynamics simulation, Monte Carlo simulation. 


\section{Introduction}

The interlayer space in smectite minerals such as montmorillonite can be easily expanded by intercalating water. ${ }^{1-33}$ Montmorillonite is a layered aluminosilicate where sheets of octahedrally coordinated $\mathrm{Al}$ atoms and tetrahedrally coordinated $\mathrm{Si}$ atoms are stacked in a 2:1 ratio to form a tetrahedral-octahedral-tetrahedral (TOT) layer. In montmorillonite, the TOT layers are negatively charged due to substitution of $\mathrm{Al}$ by $\mathrm{Mg}$ in the octahedral sheets and by less common substitution of $\mathrm{Si}$ by $\mathrm{Al}$ in the tetrahedral sheets. The negative charge of the TOT layers is compensated by counterions present in the interlayer space. Furthermore, clay minerals have significant applications in the area of nuclear waste disposal, ${ }^{34,35}$ geologic storage of $\mathrm{CO}_{2},{ }^{36-39}$ and shale gas extraction. ${ }^{36,40-42}$ They are also used in commercial applications. ${ }^{43,44}$ Of particular importance is the successful storage of carbon dioxide which is influenced by the permeability of caprock formations. Caprocks may be composed of shale or mudstone enriched in clay minerals including montmorillonite which can swell depending on the environmental conditions (e.g., relative humidity $(\mathrm{RH})$ ). A molecular-level understanding of clay- $\mathrm{H}_{2} \mathrm{O}$ interactions is essential for the development of such applications.

Extensive experimental ${ }^{1-17}$ and simulation ${ }^{18-32}$ studies have been performed to elucidate the swelling mechanism of montmorillonite systems. These studies showed that the stable basal distances are typically in the ranges of $9.5-10.5 \AA, 11.5-12.5 \AA$, $14.5-15.5 \AA$, and $18.0-19.1 \AA$ for dry (0W), monolayer (1W), bilayer $(2 \mathrm{~W})$, and three layer $(3 \mathrm{~W})$ water arrangements, respectively. Many factors affect the sorption and diffusion mechanisms of $\mathrm{H}_{2} \mathrm{O}$ and ions in clays such as layer charge, ion type, pore space, and RH. For example, Ferrage et al. ${ }^{12,13}$ experimentally studied the influences of layer charge and counterion type on the swelling behavior of montmorillonite clays with varying RH. They observed that the hydration properties of smectites are controlled by the type of interlayer cation and an increase of layer charge shifts the $0 \mathrm{~W}$-to- $1 \mathrm{~W}$ and the $1 \mathrm{~W}$-to-2W transitions toward lower $\mathrm{RH}$ values. Notably, simulations carried out with a fully flexible, rather than rigid, clay structure yielded the best agreement with 
experimental results. ${ }^{27}$ The amount of water on clay surfaces plays an important role in the gas adsorption and selectivity properties. ${ }^{45,46}$ For example, attributed to their multilayer adsorption, carbon dioxide and methane favorably adsorb onto the clay surfaces with intermediate water contents. ${ }^{46}$ The adsorption selectivity of carbon dioxide over methane decreases with pressure in dry conditions, while this trend is reversed in the presence of water. ${ }^{45,46}$ Recently, molecular simulations have been applied to study the influence of $\mathrm{RH}$ on the adsorption and dynamics of water and ions in low-charge (Wyoming-type) montmorillonite. ${ }^{26,29,31}$ However, a detailed knowledge of the effect of factors such as layer charge on adsorption and diffusion properties of $\mathrm{H}_{2} \mathrm{O}$ and ions in smectites is still lacking.

Our previous studies have shown that molecular simulations are a useful approach to assess the surface and chemical interactions. ${ }^{31,46-51}$ In this study we employ grand canonical Monte Carlo (GCMC) calculations to acquire a molecular-level description of the effect of $\mathrm{RH}$ on $\mathrm{H}_{2} \mathrm{O}$ uptake by high-charge clays (Arizona-type montmorillonite) at 298.15 K. The simulation results of basal distances obtained from swelling free energy curves and of $\mathrm{H}_{2} \mathrm{O}$ uptake were applied to aid in the interpretation of experimental measurements ${ }^{6,9,13}$ on high-charge montmorillonite clays. In addition, we performed molecular dynamics (MD) calculations to determine the mechanisms of water and ion diffusion in high-charge montmorillonite clays with varying $\mathrm{RH}$. We also compared the sorption and diffusion results of the interlayer species with those obtained from the external surfaces. We then studied the influence of the magnitude of the layer charge on the sorption and diffusion properties.

\section{Simulation details}

We performed GCMC and MD calculations using TOWHEE ${ }^{52}$ and LAMMPS ${ }^{53}$ molecular simulation packages, respectively. The simulation model and method were the same as those used in our earlier work. ${ }^{31,46,49,50}$ The clay model used in the present work was based on the unit cell of pyrophyllite $\left(\mathrm{Si}_{8} \mathrm{Al}_{4} \mathrm{O}_{20}(\mathrm{OH})_{4}\right)$. Our simulations 
employed 64 unit cells (2560 atoms) and an orthorhombic box with lateral dimensions of $42.24 \times 36.56 \AA$ (Fig. 1). We typically used two parallel clay layers each with a thickness of $6.56 \AA$. We have focused here on Arizona-type clay of unit cell formula $\mathrm{M}_{1.0 / n}\left(\mathrm{Si}_{8}\right)\left(\mathrm{Al}_{3.0} \mathrm{Mg}_{1.0}\right) \mathrm{O}_{20}(\mathrm{OH})_{4}$, where $\mathrm{M}$ denotes a cation (lithium, sodium, potassium, magnesium, calcium, or strontium) and $n$ is the charge on the ion. Therefore, each clay sheet consists of 32 isomorphic substitutions of aluminium by magnesium ion in the octahedral sheet and 32 (16) compensating monovalent (divalent) cations in the interlayer space. We made sure that Loewenstein's rule (for example, substitution sites are not adjacent to each other) is obeyed. Furthermore, the clay is held rigid during the GCMC calculations and a fully flexible clay is used for all MD simulations. Periodic boundary conditions were applied in all directions.

The general expression for the total potential energy is

$$
E_{\mathrm{Tot}}=E_{\mathrm{LJ}}+E_{\mathrm{Coul}}+E_{\mathrm{Stretch}}+E_{\text {Bend }}
$$

In the above equation, the nonbonded interactions between particles are described by pairwise Lennard-Jones (LJ) 12-6 potential: ${ }^{54}$

$$
E_{\mathrm{LJ}}=4 \varepsilon_{i j}\left[\left(\frac{\sigma_{i j}}{r_{i j}}\right)^{12}-\left(\frac{\sigma_{i j}}{r_{i j}}\right)^{6}\right]
$$

where $r_{i j}$ is the distance between the centers of $i$ and $j$ sites, and $\varepsilon_{i j}$ and $\sigma_{i j}$ are the LJ energy and distance parameters, respectively. The LJ parameters for interactions between unlike atoms were obtained by use of the Lorentz-Berthelot combining rules:

$$
\begin{gathered}
\sigma_{i j}=\frac{\sigma_{i}+\sigma_{j}}{2} \\
\varepsilon_{i j}=\sqrt{\varepsilon_{i} \varepsilon_{j}} .
\end{gathered}
$$

The nonbonded interactions between charged atoms are described by the Coulomb 
potential:

$$
E_{\text {Coul }}=\frac{q_{i} q_{j}}{4 \pi \varepsilon_{0} r_{i j}},
$$

where $q_{i}$ and $q_{j}$ are the partial charges of the sites $i$ and $j$, respectively, and $\varepsilon_{0}$ is the dielectric permittivity of vacuum. The long-range Coulombic interactions are estimated by the Ewald summation (GCMC) or particle-particle particle-mesh (MD) technique with a precision of $10^{-5}$. The nonbond cutoff for interactions was $10.0 \AA$.

Harmonic potentials are used for the bond stretch and angle bend terms:

$$
E_{\text {Stretch }}=\frac{1}{2} k_{r}\left(r_{i j}-r_{0}\right)^{2},
$$

and

$$
E_{\text {Bend }}=\frac{1}{2} k_{\theta}\left(\theta-\theta_{0}\right)^{2},
$$

where $r_{0}$ is the equilibrium bond length, $\theta$ is the bending angle, $\theta_{0}$ is the equilibrium bending angle, and $k_{r}$ and $k_{\theta}$ are the corresponding force constants. We used the CLAYFF force field ${ }^{55}$ to describe the interactions of the clay atoms. A rigid ${ }^{56}$ and a flexible ${ }^{55}$ simple point charge (SPC) water model were used in GCMC and MD simulations, respectively. The force field parameters of lithium, ${ }^{57}$ sodium, ${ }^{24,55}$ potassium, $, 55,58$ magnesium, ${ }^{57}$ calcium, ${ }^{55,58}$ and strontium ${ }^{57}$ counterions are obtained from literature. The atomic charges and LJ parameters employed in this work are given in Table 1.

The water content in the montmorillonite was calculated from GCMC calculations in the $\mu_{\mathrm{H}_{2} \mathrm{O}} V T$ ensemble $\left(\mu_{\mathrm{H}_{2} \mathrm{O}}\right.$ is the chemical potential of $\left.\mathrm{H}_{2} \mathrm{O}^{59,60}\right)$. Typically, each simulation ran for at least $6 \times 10^{7}$ Monte Carlo steps, of which first $4 \times 10^{7}$ were for equilibration. Depending on the imposed chemical potential, up to about $9 \times 10^{8}$ Monte Carlo steps were used in the case of mesopores. We obtained stable basal $d$-spacings from stability analysis based on the pressure normal to the clay platelets $P_{z z}$ (outputted by TOWHEE) and the free energy $\Delta F$ per clay platelet area $A .{ }^{24,25}$ The swelling free 
energy per clay platelet area is

$$
\Delta F / A=-\int_{d_{0}}^{d}\left(P_{z z}\left(d^{\prime}\right)-P_{\text {app }}\right) d d^{\prime}
$$

where, $d_{0}$ is the arbitrarily chosen reference basal spacing of $10.0 \AA$ ( $\approx 0 \mathrm{~W}$ state) and $P_{\text {app }}$ represents the applied pressure. In our simulations, the basal $d$-spacings of the clays were chosen in the range 10.0-15.0 $\AA$ for the swelling region up to the $2 \mathrm{~W}$ state (see below), whereas the basal $d$-spacing of the mesopore was maintained constant at $65.0 \AA$.

The isosteric heat $q_{\mathrm{st}}$ is obtained from the GCMC simulations using the fluctuation method: ${ }^{46,61}$

$$
q_{\mathrm{st}} \simeq R T-\frac{\langle U N\rangle-\langle U\rangle\langle N\rangle}{\left\langle N^{2}\right\rangle-\langle N\rangle^{2}}
$$

where $U$ and $N$ are the configurational internal energy and the number of adsorbed water molecules, respectively, and the angular brackets represent statistical averages.

The final configurations outputted by the GCMC simulations were taken as the initial configurations in the MD simulations. MD simulations were performed in the NVT ensemble. The equations of motion were integrated using the velocity Verlet algorithm with a time step of 1 fs. Temperature was controlled by a Nośe-Hoover thermostat $^{54}$ with a relaxation time of $0.1 \mathrm{ps}$. An equilibration phase of 5 ns was followed by a production run of 10 ns. Six independent trajectories each of length 15 ns were averaged to achieve good statistics. Self-diffusion coefficients along the clay surfaces were evaluated by the two-dimensional Einstein relation:

$$
D_{x y}=\lim _{t \rightarrow \infty} \frac{\left\langle\Delta x(t)^{2}+\Delta y(t)^{2}\right\rangle}{4 t},
$$

where, e.g., $\left\langle\Delta x(t)^{2}\right\rangle$ is the mean-square displacement (MSD) of the particle in the $x$ direction. 


\section{Results and discussion}

\subsection{Swelling of montmorillonite}

We performed GCMC simulations to investigate the swelling properties of montmorillonite clays with varying RH. Oscillations in the pressure are indicative of crystalline swelling properties of montmorillonte clays. ${ }^{21,25,62}$ Fig. 2 shows the results of the pressure normal to the surface $P_{z z}$ and the swelling free energy per clay platelet area $\Delta F / A$ as a function of the basal $d$-spacing for Sr-montmorillonite at $298.15 \mathrm{~K}$ (Figs. S1 and S2, Supporting Information, show the corresponding results for all studied cases). The free energy curves show distinct minima corresponding to points where $P_{z z}$ passes the applied pressure line with a negative slope. The bulk pressure and any external pressure both contribute to the applied pressure. In these simulations, the applied pressure is the partial water-vapor pressure. In Fig. 3, we compiled the resulting $d$-spacing values located at the global energy minima (symbols) in the swelling free energy curves and corresponding experimental results (lines). ${ }^{6,13}$ There is good agreement between our results and the available experimental data. Furthermore, Fig. 4 displays the $\mathrm{H}_{2} \mathrm{O}$ content in the montmorillonite as obtained from our GCMC calculations (symbols) and corresponding experimental results (lines). ${ }^{9,13}$ For simplicity and comparison purpose, basal spacings of $d=10.0,12.0$, and $15.0 \AA$ for the $0 \mathrm{~W}, 1 \mathrm{~W}$, and $2 \mathrm{~W}$ swelling states, respectively, were used in these simulations. The approximate hydration states/basal $d$-spacings and the corresponding $\mathrm{RH}$ ranges, for example, found experimentally 6,13 and employed in these simulations are given in Table 2 (see also Fig. 3). Moreover, a good qualitative agreement between the simulation and the experiment is observed for the water uptake. We think that the difference may arise mainly from the coexistence of integral hydrations states (i.e., 0W, 1W etc.) in experimental samples at a given RH. ${ }^{13}$ Also, other factors such as slight changes in basal distances between model and experiment might affect the accuracy of the results. Then to gain information on the equilibrium structures of relevant hydration states, we plot in Figs. S3 and S4, density profiles of water and ions evaluated along the $z$-axis (perpendicular to the clay surface). 
Our simulation data show that similar to the order of ion hydration energy, the swelling tendency of the clay follows: $\mathrm{Mg}->\mathrm{Ca}->\mathrm{Sr}->\mathrm{Li}->\mathrm{Na}->\mathrm{K}$-montmorillonite. We find stable basal $d$-spacings for the dry (0W) state of montmorillonite clays below about $10.5 \AA$. The interaction of montmorillonites with $\mathrm{H}_{2} \mathrm{O}$ induces swelling to the values equal to the $1 \mathrm{~W}$ state ( $d$-spacings of about $11.5-12.5 \AA)$. We see that with increasing $\mathrm{RH}$, the $d$-spacings increase to the next stable values in the range of about $14.5-15.5 \AA(2 \mathrm{~W})$. Higher hydration states such as three water layers (3W) can be formed close to or above water saturation. ${ }^{6}$ However, clay swelling mechanism for $\mathrm{RH} \gtrsim 100 \%$ is not considered in this work. Notably, in all cases the change in RH hardly influences the water content and the distribution of water and cations in each hydration state.

As in the case of water, swelling due to humidity changes significantly affects the density profiles of cations. Here we observe both inner- and outer-sphere surface complexes. An inner-sphere surface complex is formed when a cation binds directly with the clay surface. ${ }^{63}$ Whereas, a cation in the outer-sphere surface complex retains the solvation shell. Our results show that monovalent and divalent cations mostly form inner- and outer-sphere surface complexes, respectively. Similar results are found for

low-charge montmorillonite. ${ }^{24,31}$ Such a behavior can be attributed to the fact that strongly hydrated ions hinder the development of inner-sphere surface complexes. Interestingly, the presence of the inner-sphere surface complex leads to a striking stability of the $1 \mathrm{~W}$ state for the K-montmorillonite clay and inhibits further swelling of the clay. ${ }^{19,31}$

\subsection{Adsorption of $\mathrm{H}_{2} \mathrm{O}$ on the external surfaces of montmo- rillonite}

Molecular simulations can readily distinguish between the intercalated and the externally adsorbed water contents in clay minerals. Thus, simulations were also performed to provide a systematic study of adsorption of water in the mesopores of montmoril- 
lonite with varying $\mathrm{RH}$. The basal $d$-spacing of the mesopore was chosen to be $65 \AA$ in all our simulations. Fig. 5 displays the $\mathrm{H}_{2} \mathrm{O}$ content in the mesopore obtained from molecular simulations (symbols). The analysis of these results using the Brunauer, Emmett, and Teller (BET) ${ }^{64}$ isotherm model (lines) gives complementary information on the multilayer adsorption process. The fit parameters are given in Table S1. Although the BET theory is a simplification of multilayer adsorption, it describes well the initial stage of this process here. It is clear that for any given $\mathrm{RH}$, the water content is higher for samples saturated with divalent cations than for samples saturated with monovalent cations. The monolayer coverages of monovalent and divalent cases from BET analysis, for instance, are about 6 and $9 \mathrm{H}_{2} \mathrm{O}$ molecules per $\mathrm{O}_{20}(\mathrm{OH})_{4}$, respectively. We see that the BET model does not adequately describe adsorption of water vapor by montmorillonite at high $\mathrm{RH}$ values as noted earlier. ${ }^{15}$ The comparison between gravimetric and X-ray diffraction results can be used to discriminate the relative contributions of water located in smectite interlayers and on external clay surfaces. ${ }^{12}$ Our results show that under a similar condition, relative contribution of water in the mesopore is significant near the saturation pressure (see, for example, Figs. 4 and 5). We find that these differences begin to appear well below the saturation value. Notably, this behavior for K-montmorillonite is because of clay-swelling inhibition by $\mathrm{K}^{+}$. We see that for mesopores, complete filling of the pore volume does not occur in the GCMC simulations until the pressure is about 1.2 times higher than the bulk vapor pressure of SPC water. This may be because the environment for hydrogen bonding is unfavorable relative to the bulk liquid state. A similar behavior was also found in other adsorbents. ${ }^{65,66}$

We also calculated the equilibrium density profiles showing the arrangement of $\mathrm{H}_{2} \mathrm{O}$ and counterions in the mesopore (Figs. S5-S6). In all cases, we observe bulk-like properties of water away from the surfaces $(z \gtrsim 10 \AA)$ at high $\mathrm{RH}$ conditions. For water saturated systems $(\approx 100 \% \mathrm{RH})$, the profiles show three clear peaks of water located at $z \approx 3,6$, and $9 \AA$ in good agreement with earlier studies. ${ }^{26,67}$ The number and/or magnitude of the water peaks increase with $\mathrm{RH}$ and seem to follow the pattern 
of the water saturated systems. For example, the water density profiles compare well with those of the saturated systems up to $z \approx 3 \AA$ at $40 \% \mathrm{RH}$ and up to $z \approx 6 \AA$ at $80 \% \mathrm{RH}$, especially for the strongly hydrated ions in the latter case. As RH and/or hydration energy increase, the ions move away from the clay surfaces, thus forming outer-sphere surface complexes. The maxima in distribution of ions, associated with the outer-sphere complexes, coincide with the minima in the water density profiles between the first and second $\mathrm{H}_{2} \mathrm{O}$ layers. Our results show that, as $\mathrm{RH}$ increases, counterions associated with outer-sphere surface complexes gradually accumulate in the diffuse-layer. The later is located beyond the first two water monolayers and the detailed characteristics of this diffuse-layer in mesopores could also be determined by the solution of the Poisson-Boltzmann equation. ${ }^{68}$ Churakov observed similar results for low-charge montmorillonite clays. ${ }^{26}$ Notably, earlier studies in the fields of electrokinetics and supercapacitors show similar features as those reported in this study (see, e.g., Figs. S3-S6). ${ }^{69-71}$

The formation of surface complexes and differences in adsorption are also evident from the calculated radial distribution functions (RDFs) of ion-water and ion-surface oxygens (Figs. S7-S10). For example, the peaks for water molecules in the first hydration shells around ions are located at about 2-3 A. In this region, we can see also that the ions tend to be coordinated by surface oxygens (inner-sphere complexes) or by water molecules alone (outer-sphere complexes). As expected, over most of the RH range, the amounts of interlayer water in the first hydration shells (Figs. S11-S14) around potassium ions are lower as compared to those of the mesopore.

Fig. 6 shows the simulated isosteric heat values for water adsorption on the montmorillonite as a function of RH. The isosteric heats were calculated from the fluctuations of the energy (see eq. (9)). ${ }^{46,61}$ The isosteric heat is related to the surface energetic heterogeneity and the fluid-fluid interaction. It can be seen that the isosteric heat decreases with increasing RH. This is because when water loading is increased, molecules are now further from the surface, giving lower solid-fluid interaction. The simulated isosteric heats of the $1 \mathrm{~W}-2 \mathrm{~W}$ states are in the range of about $12-15 \mathrm{kcal} / \mathrm{mol}$ (see Fig. 
6a). These values are in good agreement with the experimental results obtained from the isotherms recorded at three temperatures. ${ }^{72}$ At a given $\mathrm{RH}$, the isosteric heats of adsorption of water are relatively lower for the mesopores (see Fig. 6b) as expected. Also here the isosteric heats above about $80 \% \mathrm{RH}$ remain unchanged and equal to the heat of vaporization of pure water. Furthermore, in a given hydration state or in the mesopore, the isosteric heats are found to be similar for all counterions.

\subsection{Diffusion of $\mathrm{H}_{2} \mathrm{O}$ and counterions in montmorillonite in- terlayers}

Figs. S15-S16 show typical MSDs of $\mathrm{H}_{2} \mathrm{O}$ and counterions in the interlayers of montmorillonite. Tables S2-S3 show the self-diffusion constants calculated from the linear slope of the displacement vs time plots. The estimated diffusion coefficients of water and ions are generally consistent with experiments ${ }^{14,17}$ and previous simulation results ${ }^{27,30}$ (see, for example, Table S2). The quasi-elastic neutron scattering techniques are suitable to study water dynamics on the scales which can also be probed by MD simulations. ${ }^{14}$ However, typically experimental measurements report the continuum-scale apparent diffusion coefficients for water and cations which depend on many factors such as tortuosity, pore-size variability etc. For example, the macroscopic scale diffusion values of water and its diffusion coefficients in the interlayer nanopores are offset by a factor of about $4 .^{27}$ Furthermore, Fig. 7 shows the normalized diffusion coefficients as a function of RH. Here we chose the bulk values from water-saturated mesopores (see below) which are close to the experimental ones. ${ }^{73,74}$

Our results show that the diffusion coefficients of water and ions in a given hydration state are not much affected by changes in RH. This is similar to the behavior of the sorbed amount of water and the various density profiles, as discussed above. Except for divalent ions, the diffusion coefficient of each species in the $1 \mathrm{~W}$ hydration state is about 1-2 orders of magnitude lower than the bulk. The diffusion coefficient of a divalent ion in the same state is about 2-3 orders of magnitude lower than the bulk. 
As expected, the mobility of water and ions increases as a function of RH because of the related expansion of the basal spacings. However, this effect is not observed in the case of $\mathrm{K}$-montmorillonite since $\mathrm{K}^{+}$act as a clay swelling inhibitor. It can be seen that the self-diffusion coefficients of $\mathrm{H}_{2} \mathrm{O}$ in hydration states of montmorillonites saturated with divalent counterions are typically lower than with monovalent counterions. This is in line with the observations for the solvation energies. ${ }^{75}$ Comparing with the solvation energies of divalent ions (e.g., $\approx-477.6 \mathrm{kcal} / \mathrm{mol}$ for $\mathrm{Mg}^{2+}$ ), the lower solvation energies of monovalent ions (e.g., $\approx-86.1 \mathrm{kcal} / \mathrm{mol}$ for $\mathrm{K}^{+}$) indicate a looser solvation shell around the monovalent ions. This fact suggests a higher mobility of water associated with the monovalent ions than with the divalent ions. ${ }^{28,30}$ However, there are exceptions, e.g., water is less mobile in the $1 \mathrm{~W}$ hydration state of Li-montmorillonite possibly due to the presence of inner-sphere surface complexes. Interestingly, in the presence of $\mathrm{CO}_{2}$, the water diffusion is more restricted in Cs-montmorillonite when compared to K-montmorillonite. ${ }^{76}$

\subsection{Diffusion of $\mathrm{H}_{2} \mathrm{O}$ and counterions in mesopores}

Figs. S17-S18 show typical MSDs of $\mathrm{H}_{2} \mathrm{O}$ and counterions in the mesopores of montmorillonite. Tables S4-S5 show the self-diffusion constants calculated from the linear slope of the displacement vs time plots. Furthermore, Fig. 8 shows the normalized diffusion coefficients as a function of RH. Our results show that ionic mobilities monotonically increase with increasing $\mathrm{RH}$ in all cases. This behavior is expected because the density distributions show a shift from, for instance, the inner- to the outer-sphere surface complexes with increasing RH (see, for example, Figs. S5-S6). Also, it must be noted that the number of surface oxygens in the first coordination shells of the counterions decreases and $\mathrm{H}_{2} \mathrm{O}$ becomes part of these shells as $\mathrm{RH}$ increases ${ }^{26}$ (see, for example, Figs. S13-S14). The association of water with the surface-bound ions decreases with increasing RH, and therefore water mobility increases.

At a given RH, probably due to steric reasons, the self-diffusion coefficients of water and ions in the interlayer regions are generally lower than those in the mesopore (see, 
for example, Figs. 7 and 8$)$. The species mobility in the $1 \mathrm{~W}$ hydration state $(\approx 20 \%$ $\mathrm{RH}$ ), for instance, is about 1-2 orders of magnitude lower than that in water films. This difference in mobilities becomes smaller with increasing $\mathrm{RH}$ for all cases, except K-montmorillonite which shows a limited swelling.

Overall, the ion solvation energy and steric effects may play important roles in determining the swelling state and the diffusion properties. For example, among the monovalent systems, an interlayer species in the K-montmorillonite is generally the least mobile at all RH due to the clay-swelling inhibition. However, the swelling states are generally similar among the divalent systems at all RH (see, e.g., Table 2). Therefore, a higher mobility of the interlayer species in Sr-montmorillonite may be due to the lower solvation energy of $\mathrm{Sr}^{2+}$ which suggests a looser solvation shell. In mesopores, among the monovalent systems, potassium ion which forms stable inner-sphere surface complex is generally the least mobile at all RH, whereas water in K-montmorillonite exhibits a higher mobility. Here again the adsorbed species in Sr-montmorillonite generally show a higher mobility among the divalent systems.

\subsection{Influence of layer charge}

Here we compare simulation data of low-charge $\left(\mathrm{M}_{0.75 / n}\left(\mathrm{Si}_{7.75} \mathrm{Al}_{0.25}\right)\left(\mathrm{Al}_{3.5} \mathrm{Mg}_{0.5}\right) \mathrm{O}_{20}(\mathrm{OH})_{4}\right)$ and high-charge (see above) montmorillonite clays. GCMC simulations of this lowcharge montmorillonite (Wyoming-type) in contact with water can be found elsewhere. ${ }^{31}$ Note that a rigid framework of clay was employed in all our previous work. ${ }^{31}$ Furthermore, as in the case of the high-charge system, flexible models of water and clay are used here for new MD simulations of the low-charge system.

The comparison shows that the high-charge clay generally shifts swelling transitions toward lower RH values consistent with experiments ${ }^{6,13}$ (see, for example, Tables 2 and S6). Notably, this shift seems to be less pronounced for weakly hydrated ions such as potassium. For example, Fig. 9 shows the variations of the normal pressure and the swelling free energy per clay platelet area as a function of the basal $d$-spacing of the low- and high-charge Sr-montmorillonite at $\mathrm{RH}$ values of 10 and 30\%. It is evident 
from the figure that the $1 \mathrm{~W}$ state with basal $d$-spacing of about $12 \AA$ and the $2 \mathrm{~W}$ state with basal $d$-spacing of about $15 \AA$ are stable for the low- and high-charge Sr-montmorillonite, respectively, at $30 \% \mathrm{RH}$. However, the $1 \mathrm{~W}$ hydration state with basal $d$-spacing of about $12 \AA$ is the stable state for both cases at $10 \%$ RH. It can be inferred that layer charge plays a major role in determining the hydration state of the clay mineral. A similar trend was found in previous experimental study of synthetic Na-saturated saponites. ${ }^{77}$ Such behavior was also observed in the presence of carbon dioxide. ${ }^{78}$ This is probably due to the fact that high-charge clays contain a relatively large number of hydrated cations. Therefore, it can be seen that, the amount of adsorbed water is significantly different in the low- and high-charge clays near the transition RH values. Also, for a given hydration state, the water content per $\mathrm{O}_{20}(\mathrm{OH})_{4}$ is mostly independent of the magnitude of the layer charge, possibly due to steric reasons (see, for example, Fig. 4 and ref. 29). That is, the water content per cation decreases with increasing layer charge. Our results show that, for a given $\mathrm{RH}$, the water content per $\mathrm{O}_{20}(\mathrm{OH})_{4}$ in the mesopores of montmorillonite generally increases with layer charge (see, for example, Fig. 5 and ref. 29). For example, the ratio between the monolayer coverage of low- and high-charge montmorillonite obtained from the BET fits is about 0.6 in all cases. That is, the water content per cation is almost constant with increasing layer charge.

It is important to note that our high-charge montmorillonite model has only octahedral substitutions, while the low-charge clay used here contains both tetrahedral and octahedral substitutions. For a given layer charge, the swelling process with respect to the basal distance and the $\mathrm{H}_{2} \mathrm{O}$ uptake was not much influenced by the layer charge distributions. ${ }^{31}$ However, the water content per $\mathrm{O}_{20}(\mathrm{OH})_{4}$ in the mesopores of montmorillonite decreased in the presence of tetrahedral substitutions. ${ }^{31}$ For example, the ratio between the monolayer coverage of low- (no tetrahedral $\mathrm{Al}$ ) and high-charge montmorillonite obtained from the BET fits is about 0.7 in all cases. Overall, in a given hydration state or in the mesopore, the density profiles of $\mathrm{H}_{2} \mathrm{O}$ and counterions (Figs. S19-S22) and RDFs (Figs. S23-S30) were not much affected by the increasing layer 
charge. At a fixed $\mathrm{RH}$, however, the layer charge can significantly affect the density profiles and rdfs because of the fact that the high-charge clay shifts swelling transitions toward lower $\mathrm{RH}$ values. As expected, the presence of tetrahedral substitutions leads to a relative increase in the amount of the inner-sphere surface complexes in the low-charge case. A similar behavior was also observed for the simulated isosteric heats of adsorption of water.

Factors such as the steric effects and the enhanced electrostatic interactions may play important roles in the diffusion process. We see that the self-diffusion coefficients of water and ions in the high-charge montmorillonite are generally lower than those of the corresponding low-charge system (see Tables S2-S5 and S7-S10, and Fig. S31). An opposite trend is expected near the transition $\mathrm{RH}$ values due to the fact that the high-charge clay shifts swelling transitions toward lower RH values. Notably, in the low-charge montmorillonite, for not too low RH and weakly hydrated ions, the diffusion coefficients of $\mathrm{H}_{2} \mathrm{O}$ present on the external surfaces were also higher than those in the water-saturated mesopores. ${ }^{26,31}$ This was attributed to the fewer hydrogen bonds ${ }^{79}$ at the liquid-vapor interface which reduce the effective friction experienced by water molecules, resulting in higher diffusion coefficients. Interestingly, the mobility of cations in the mesopores of high-charge montmorillonite is typically higher than that of the corresponding low-charge system. This may be attributed to the relatively stronger cation-surface interactions due to the presence of tetrahedral substitutions in the low-charge montmorillonite (see, for example, Figs. S21-S22). Note that the high-charge system has only inner octahedral substitutions in our simulations. Such confinement and surface charge effects can also influence, e.g., the electrokinetic transport in nanochannels. ${ }^{70}$

Overall, one of the main effects of layer charge on adsorption and diffusion properties is due to the shifts in the swelling transitions. Thus the major differences in such properties are restricted to narrow regions of $\mathrm{RH}$ lying between the swelling transitions of the low- and high-charge clays. We confirmed that these shifts in swelling transitions are more pronounced for strongly hydrated ions. Also, the interlayer water content per 
cation in a hydration state decreases with increasing layer charge. However, the water content per cation in the mesopore is almost constant with increasing layer charge. We note that both the magnitude and the distribution of layer charges play important roles in diffusion processes.

\section{Conclusions}

GCMC and MD calculations were applied to investigate the adsorption and diffusion properties of $\mathrm{H}_{2} \mathrm{O}$ and ions in interlayers and on external surfaces of high-charge montmorillonite clays (Arizona-type) with varying RH. In total, six counterions were considered in this work: lithium, sodium, potassium, magnesium, calcium, and strontium. The simulation results of basal distances derived from the swelling free energy curves and the quantity of adsorbed water were in agreement with experimental observations. ${ }^{6,9,13}$ We find that the cation solvation energy plays a key role in the swelling

mechanism of clays. In general, for weakly solvated ions (e.g., $\mathrm{K}^{+}$), the amounts of water adsorbed on the external clay surfaces were significantly higher than those in the interlayers. This can be attributed to the clay swelling inhibition by such cations. Furthermore, the estimated self-diffusion coefficients of intercalated $\mathrm{H}_{2} \mathrm{O}$ and counterions were consistent with experiments. ${ }^{14,17}$ At a fixed $\mathrm{RH}$, possibly due to steric factors, the simulated diffusion coefficients of the interlayer species were generally lower than those calculated for the external surfaces. This difference in mobilities becomes smaller with increasing RH for all cases, except clays saturated with weakly solvated ions which exhibit a limited swelling.

The effect of the layer charge on adsorption and diffusion of $\mathrm{H}_{2} \mathrm{O}$ and ions in clays was investigated by comparing the simulation results obtained for high-charge (Arizona-type) and low-charge (Wyoming-type) montmorillonites. Our comparisons confirm the experimental observation that the high-charge montmorillonite generally shifts swelling transitions toward lower $\mathrm{RH}$ values, probably because of the fact that the high-charge clays contain a relatively large number of hydrated cations. Therefore, 
we see that the adsorption and dynamics of water and ions near the transition $\mathrm{RH}$ values are significantly different in the low- and high-charge montmorillonites. An important finding is that for a given interlayer hydration state, possibly due to steric reasons, the water content per $\mathrm{O}_{20}(\mathrm{OH})_{4}$ is almost independent of the layer charge. However, at a given $\mathrm{RH}$, the water content per $\mathrm{O}_{20}(\mathrm{OH})_{4}$ in the mesopore increases with increasing magnitude of the layer charge. The self-diffusion coefficients of water and ions in the high-charge clay are generally lower than those of the corresponding low-charge system. As an exception to this, the diffusion coefficients of counterions in the mesopores of high-charge montmorillonite are typically higher than those of the corresponding low-charge system. This may be attributed to the presence of the tetrahedral substitutions in the low-charge montmorillonite. These findings should provide a basis for future studies, e.g., on the influence of geological conditions on clay swelling processes at varying relative humidity.

\section{Acknowledgments}

This publication is partly based upon work supported by the KAUST Office of Sponsored Research (OSR) under Award No. 2993. Y. Y. and A. K. N. N. like to thank KAUST for providing computer time.

\section{Supporting Information}

Additional details of simulation analysis are given in the Supporting Information. 


\section{References}

(1) Romanov, V., ed. Greenhouse Gases and Clay Minerals: Enlightening Down-toearth Road Map to Basic Science of Clay-greenhouse Gas Interfaces; Springer, 2018

(2) Norrish K. The swelling of montmorillonite. Discuss. Faraday Soc. 1954, 18, $120-134$.

(3) Foster, W. R.; Savins, J. G.; Waite, J. M. Lattice Expansion and Rheological Behavior Relationships in Water-Montmorillonite Systems. Clays Clay Miner. 1955, 3, 296-316.

(4) Keren, R.; Shainberg, I. Water Vapor Isotherms and Heat of Immersion of Na/CaMontmorillonite Systems-I: Homoionic Clay. Clays Clay Miner. 1975, 23, $193-$ 200.

(5) Fu, M. H.; Zhang, Z. Z.; Low, P. F. Changes in the Properties of a Montmorillonite-Water System During the Adsorption and Desorption of Water: Hysteresis. Clays Clay Miner. 1990, 38, 485-492.

(6) Sato, T.; Watanabe, T.; Otsuka, R. Effects of Layer Charge, Charge Location, and Energy Change on Expansion Properties of Dioctahedral Smectites. Clays Clay Miner. 1992, 40, 103-113.

(7) Berend, I.; Cases, J.; Francois, M.; Uriot, J. P.; Michot, L. J.; Masion, A.; Thomas, F. Mechanism of Adsorption and Desorption of Water Vapor by Homoionic Montmorillonites: 2. The $\mathrm{Li}^{+}, \mathrm{Na}^{+}, \mathrm{K}^{+}, \mathrm{Rb}^{+}$, and $\mathrm{Cs}^{+}$-Exchanged Forms. Clays Clay Miner. 1995, 43 (3), 324336.

(8) Cases, J. M.; Berend, I.; Francois, M.; Uriot, J. P.; Michot, L. J.; Thomas, F. Mechanism of Adsorption and Desorption of Water Vapor by Homoionic Montmorillonite: 3. The $\mathrm{Mg}^{2+}, \mathrm{Ca}^{2+}, \mathrm{Sr}^{2+}$ and $\mathrm{Ba}^{2+}$ Exchanged Forms. Clays Clay Miner. 1997, $45(1), 8-22$. 
(9) Chiou, C. T.; Rutherford, D. W. Effects of Exchanged Cation and Layer Charge on the Sorption of Water and EGME Vapors on Montmorillonite Clays. Clays Clay Miner. 1997, 45, 867-880.

(10) Dios Cancela, G.; Huertas, F. J.; Romero Taboada, E.; Sanchez-Rasero, F.; Hernandez Laguna, A. Adsorption of Water Vapor by Homoionic Montmorillonites. Heats of Adsorption and Desorption. J. Colloid Interface Sci. 1997, 185, 343354.

(11) Xu, W.; Johnston, C. T.; Parker, P.; Agnew, S. F. Infrared Study of Water Sorption on Na-, Li-, Ca-, and Mg-Exchanged (SWy-1 and SAz-1) Montmorillonite. Clays Clay Miner. 2000, 48 (1), 120-131.

(12) Ferrage, E.; Lanson, B.; Sakharov, B. A.; Drits, V. A. Investigation of Smectite Hydration Properties by Modeling Experimental X-ray Diffraction Patterns: Part I. Montmorillonite Hydration Properties. Am. Mineral. 2005, 90, 1358-1374.

(13) Ferrage, E.; Lanson, B.; Sakharov, B. A.; Geoffroy, N.; Jacquot, E.; Drits, V. A. Investigation of Dioctahedral Smectite Hydration Properties by Modeling of X-ray Diffraction Profiles: Influence of Layer Charge and Charge Location. Am. Mineral. 2007, 92, 1731-1743.

(14) Malikova, N.; Cadene, A.; Marry, V.; Dubois, E.; Turq, P. Diffusion of Water in Clays on the Microscopic Scale: Modeling and Experiment. J. Phys. Chem. B 2006, 110 (7), 3206-3214.

(15) Hatch, C. D.; Wiese, J. S.; Crane, C. C.; Harris, K. J.; Kloss, H. G.; Baltrusaitis, J. Water Adsorption on Clay Minerals as a Function of Relative Humidity: Application of BET and Freundlich Adsorption Models. Langmuir 2012, 28, 1790-1803.

(16) Dazas, B.; Ferrage, E.; Delville, A.; Lanson, B. Interlayer structure model of trihydrated low-charge smectite by X-ray diffraction and Monte Carlo modeling in the grand canonical ensemble. Am. Mineral. 2014, 99 (36), 17241735. 
(17) Salles, F.; Douillard, J.M.; Bildstein, O.; El Ghazi, S.; Prelot, B.; Zajac, J.; Van Damme, H. Diffusion of Interlayer Cations in Swelling Clays as a Function of Water Content: Case of Montmorillonites Saturated with Alkali Cations. J. Phys. Chem. C 2015, 119 (19), 10370-10378.

(18) Boek, E. S. ; Coveney, P. V.; Skipper, N. T. Molecular Modeling of Clay Hydration: A Study of Hysteresis Loops in the Swelling Curves of Sodium Montmorillonites. Langmuir 1995, 11 (12), 46294631.

(19) Boek, E. S. ; Coveney, P. V.; Skipper, N. T. Monte Carlo Molecular Modeling Studies of Hydrated Li-, Na-, and K-Smectites: Understanding the Role of Potassium as a Clay Swelling Inhibitor. J. Am. Chem. Soc. 1995, 117 (50), 1260812617.

(20) Chang, F.-R. C.; Skipper, N. T.; Sposito, G. Computer Simulation of Interlayer Molecular Structure in Sodium Montmorillonite Hydrates. Langmuir 1995, 11, 27342741.

(21) Young, D. A.; Smith, D. E. Simulations of clay mineral swelling and hydration: Dependence upon interlayer ion size and charge. J. Phys. Chem. B 2000, 104, 9163-9170.

(22) Chávez-Páez, M.; Van Workum, K.; De Pablo, L.; de Pablo, J. J. Monte Carlo simulations of Wyoming sodium montmorillonite hydrates. J. Chem. Phys. 2001, $114(3), 1405-1413$.

(23) Marry, V.; Turq, P. Microscopic simulations of interlayer structure and dynamics

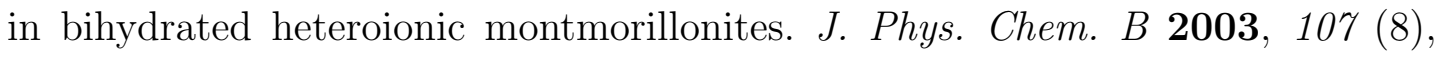
1832-1839.

(24) Whitley, H. D.; Smith, D. E. Free energy, energy, and entropy of swelling in Cs-, Na-, and Sr-montmorillonite clays. J. Chem. Phys. 2004, 120 (11), 5387-5395.

(25) Tambach, T. J.; Bolhuis, P. G.; Hensen, E. J.; Smit, B. Hysteresis in clay swelling 
induced by hydrogen bonding: accurate prediction of swelling states. Langmuir 2006, 22 (3), 1223-1234.

(26) Churakov, S. V. Mobility of Na and Cs on Montmorillonite Surface under Partially Saturated Conditions. Environ. Sci. Technol. 2013, 47, 98169823.

(27) Holmboe, M.; Bourg, I.C. Molecular Dynamics Simulations of Water and Sodium Diffusion in Smectite Interlayer Nanopores as a Function of Pore Size and Temperature. J. Phys. Chem. C 2014, 118 (2), 1001-1013.

(28) Zhang, L.; Lu, X.; Liu, X.; Zhou, J.; Zhou, H. Hydration and Mobility of Interlayer Ions of $\left(\mathrm{Na}_{x}, \mathrm{Ca}_{y}\right)$-Montmorillonite: A Molecular Dynamics Study. J. Phys. Chem. C 2014, 118, 29811-29821.

(29) Teich-McGoldrick, S.L.; Greathouse, J.A.; Jove-Colon, C.F.; Cygan, R.T. Swelling properties of montmorillonite and beidellite clay minerals from molecular simulation: comparison of temperature, interlayer cation, and charge location effects. J. Phys. Chem. C 2015, 119 (36), 20880-20891.

(30) Greathouse, J.A.; Cygan, R.T.; Fredrich, J.T.; Jerauld, G.R. Molecular Dynamics Simulation of Diffusion and Electrical Conductivity in Montmorillonite Interlayers. J. Phys. Chem. C 2016, 120 (3), 1640-1649.

(31) Li, Y.; Nair, A. K. N.; Kadoura, A.; Yang, Y.; Sun, S. Molecular Simulation Study of Montmorillonite in Contact with Water. Ind. Eng. Chem. Res. 2019, 58 (3), 1396-1403.

(32) Lee, M. S.; McGrail, B. P.; Glezakou, V. A. Microstructural Response of Variably Hydrated Ca-rich Montmorillonite to Supercritical $\mathrm{CO}_{2}$. Environ. Sci. Technol. 2014, $48(15), 86128619$.

(33) Berghout, A.; Tunega, D.; Zaoui, A. Density Functional Theory (DFT) Study of the Hydration Steps of $\mathrm{Na}^{+} / \mathrm{Mg}^{2+} / \mathrm{Ca}^{2+} / \mathrm{Sr}^{2+} / \mathrm{Ba}^{2+}$-Exchanged Montmorillonites. Clays Clay Miner. 2010, 58 , 174-187. 
(34) Pusch, R. Clays and Nuclear Waste Management. In Handbook of Clay Science; 2nd ed.; Bergaya, F.; Theng, B. K. G.; Lagaly, G., Eds.; Elsevier: Amsterdam, 2006; Vol. 1, pp 703716.

(35) Sellin, P.; Leupin, O. X. The Use of Clay as an Engineered Barrier in RadioactiveWaste Management-A Review. Clays Clay Miner. 2013, 61 (6), 477-498.

(36) Busch, A.; Alles, S.; Gensterblum, Y.; Prinz, D.; Dewhurst, D. N.; Raven, M. D.; Stanjek, H.; Krooss, B. M. Carbon dioxide storage potential of shales. Int. J. Greenhouse Gas Control 2008, 2, 297-308.

(37) Giesting, P.; Guggenheim, S.; Koster van Groos, A. F.; Busch, A. Interaction of carbon dioxide with Na-exchanged montmorillonite at pressures to 640 bar: Implications for $\mathrm{CO}_{2}$ sequestration. Int. J. Greenhouse Gas Control 2012, 8, 73-81.

(38) Romanov, V. N. Evidence of irreversible $\mathrm{CO}_{2}$ intercalation in montmorillonite. Int. J. Greenhouse Gas Control 2013, 81, 220-226.

(39) Schaef, H. T.; Loring, J. S.; Glezakou, V. A.; Miller, Q. R.; Chen, J.; Owen, A. T.; Lee, M. S.; Ilton, E. S.; Felmy, A. R.; McGrail, B. P.; Thompson, C. J. Competitive sorption of $\mathrm{CO}_{2}$ and $\mathrm{H}_{2} \mathrm{O}$ in 2:1 layer phyllosilicates. Geochim. Cosmochim. Acta 2015, 161, 248-257.

(40) Javadpour, F.; Fisher, D.; Unsworth, M. Nanoscale Gas Flow in Shale Gas Sediments. J. Can. Petrol. Technol. 2007, 46 (10), 55-61.

(41) Ross, D.J.K.; Bustin, R. M. The importance of shale composition and pore structure upon gas storage potential of shale gas reservoirs. Mar. Pet. Geol. 2009, 26 (6), 916-927.

(42) Liu, D.; Yuan, P.; Liu, H.; Li, T.; Tan, D.; Yuan, W.; He, H. High-pressure adsorption of methane on montmorillonite, kaolinite and illite. Appl. Clay Sci. 2013, 85, 25-30. 
(43) Carretero, M.I. Clay Minerals and Their Beneficial Effects Upon Human Health. A Review. Appl. Clay Sci. 2002, 21 (3), 155-163.

(44) Hanczyc, M.M.; Fujikawa, S.M.; Szostak, J.W. Experimental Models of Primitive Cellular Compartments: Encapsulation, Growth, and Division. Science 2003, 302 (56453), 618-622.

(45) Chong, L.; Myshakin E. M. Molecular Simulations of Competitive Adsorption of Carbon Dioxide - Methane Mixture on Illitic Clay Surfaces. Fluid Ph. Equilibria 2018, 472, 185-195.

(46) Kadoura, A.; Nair, A. K. N.; Sun, S. Adsorption of Carbon Dioxide, Methane and their Mixture by Montmorillonite in the Presence of Water. Microporous Mesoporous Mater. 2016, 225, 331-341.

(47) Kumar, N.A.; Seidel, C. Polyelectrolyte Brushes with Added Salt. Macromolecules 2005, 38 (22), 9341-9350.

(48) Nair, A.K.N.; Uyaver, S.; Sun, S. Conformational Transitions of a Weak Polyampholyte. J. Chem. Phys. 2014, 141 (13), 134905.

(49) Kadoura, A.; Nair, A. K. N.; Sun, S. Molecular Dynamics Simulations of Carbon Dioxide, Methane, and their Mixture in Montmorillonite Clay Hydrates. J. Phys. Chem. C 2016, 120, 1251712529.

(50) Kadoura, A.; Nair, A. K. N.; Sun, S. Molecular Simulation Study of Montmorillonite in Contact with Variably Wet Supercritical Carbon Dioxide. J. Phys. Chem. C 2017, 121 (11), 6199-6208.

(51) Yang, Y.; Nair, A. K. N.; Sun, S. Molecular Dynamics Simulation Study of Carbon Dioxide, Methane, and Their Mixture in the Presence of Brine. J. Phys. Chem. B 2017, 121 (41), 9688-9698. 
(52) Martin, M. G. MCCCS Towhee: A Tool for Monte Carlo Molecular Simulation. Mol. Simul. 2013, 39, 12121222.

(53) Plimpton, S. Fast parallel algorithms for short-range molecular dynamics. J. Comput. Phys. 1995, 117, 1-19.

(54) Frenkel, D.; Smit, B. Understanding Molecular Simulation: From Algorithms to Applications; Academic Press: London, 2002.

(55) Cygan, R. T.; Liang, J. J.; Kalinichev, A. G. Molecular Models of Hydroxide, Oxyhydroxide, and Clay Phases and the Development of a General Force Field. J. Phys. Chem. B 2004, 108 (4), 1255-1266.

(56) Berendsen, H. J. C.; Grigera, J. R.; Straatsma, T. P. The Missing Term in Effective Pair Potentials. J. Phys. Chem. 1987, 91, 6269-6271.

(57) Åqvist, J. Ion-Water Interaction Potentials Derived from Free Energy Perturbation Simulations. J. Phys. Chem. 1990, 94 (21), 8021-8024.

(58) Koneshan, S.; Rasaiah, J. C.; LyndenBell, R. M.; Lee, S. H. Solvent Structure, Dynamics, and Ion Mobility in Aqueous Solutions at $25^{\circ}$ C. J. Phys. Chem. B 1998, $102(21), 4193-4204$.

(59) Errington, J. R.; Panagiotopoulos, A. Z. A Fixed Point Charge Model for Water Optimized to the Vapor-Liquid Coexistence Properties. J. Phys. Chem. B 1998, $102(38), 7470-7475$.

(60) J.-C. Liu; P. A. Monson Monte Carlo Simulation Study of Water Adsorption in Activated Carbon. Ind. Eng. Chem. Res. 2016, 45 (16), 5649-5656.

(61) Vuong, T.; Monson, P. A. Monte Carlo Simulation Studies of Heats of Adsorption in Heterogeneous Solids. Langmuir 1996, 12, 5425-5432.

(62) Israelachvili, J. N. Adhesion Forces between Surfaces in Liquids and Condensable Vapours. Surf. Sci. Rep. 1992, 14, 109-159. 
(63) Sposito, G.; Skipper, N. T.; Sutton, R.; Park, S.-H.; Soper, A. K.; Greathouse, J. A. Surface Geochemistry of the Clay Minerals. Proc. Natl. Acad. Sci. U.S.A. 1999, 96, 3358-3364.

(64) Brunauer, S.; Emmett, P. H.; Teller, E. Adsorption of Gases in Multimolecular Layers. J. Am. Chem. Soc. 1938, 60, 309-319.

(65) Liu J. -C.; Monson, P. A. Does Water Condense in Carbon Pores? Langmuir 2005, 21, 10219-10225.

(66) Debbarma R.; Malani, A. Comparative Study of Water Adsorption on a $\mathrm{H}^{+}$and $\mathrm{K}^{+}$Ion Exposed Mica Surface: Monte Carlo Simulation Study. Langmuir 2016, 32, 1034-1046.

(67) Marry, V.; Rotenberg, B.; Turq, P. Structure and Dynamics of Water at a Clay Surface from Molecular Dynamics Simulation. Phys. Chem. Chem. Phys. 2008, $10,48024813$.

(68) Rotenberg, B.; Marry, V.; Dufrche, J. F.; Malikova, N.; Giffaut, E.; Turq, P. Modelling Water and Ion Diffusion in Clays: A Multiscale Approach. C. R. Chim. 2007, 10 (10), 1108-1116.

(69) Qiao, R.; Aluru, N. R. Ion Concentrations and Velocity Profiles in Nanochannel Electroosmotic Flows. J. Chem. Phys. 2003, 118 (10), 4692-4701.

(70) Qiao, R.; Aluru, N. R. Scaling of Electrokinetic Transport in Nanometer Channels. Langmuir 2005, 21 (19), 8972-8977.

(71) Feng, G.; Qiao, R.; Huang, J.; Sumpter, B. G.; Meunier, V. Ion Distribution in Electrified Micropores and Its Role in the Anomalous Enhancement of Capacitance. ACS Nano 2010, 4 (4), 2382-2390.

(72) Belhocine, M.; Haouzi, A.; Bassou, G.; Phou, T.; Maurin, D.; Bantignies, J. L.; Henn, F. Isosteric Heat of Water Adsorption and Desorption in Homoionic Alkaline-Earth Montmorillonites. Chem. Phys. 2018, 501 (19), 26-34. 
(73) Vanysek, P. Ionic Conductivity and Diffusion at Infinite Dilution. In CRC Handbook of Chemistry and Physics, 84th ed.; Lide, D. R., Ed.; CRC Press: Boca Raton, FL, 2003.

(74) Holz, M.; Heil, S. R.; Sacco, A. Temperature-Dependent Self-Diffusion Coefficients of Water and Six Selected Molecular Liquids for Calibration in Accurate ${ }^{1}$ H NMR PFG Measurements. Phys. Chem. Chem. Phys. 2000, 2, 47404742.

(75) Franks, F. Aqueous Solutions of Simple Electrolytes; Springer: New York, 1973; Vol. 3, p 472.

(76) Sena, M.M.; Krishnan, M. Role of Cations in Adsorption of Supercritical Carbon Dioxide at Smectite Mineral Water Interfaces: Molecular Dynamics and Adaptive Biasing Force Simulation Studies. J. Phys. Chem. C 2019, 123, 1170-1184.

(77) Dazas, B.; Lanson, B.; Delville, A.; Robert, J.L.; Komarneni, S.; Michot, L.J.; Ferrage, E. Influence of Tetrahedral Layer Charge on the Organization of Interlayer Water and Ions in Synthetic Na-Saturated Smectites. J. Phys. Chem. C 2015, $119(8), 4158-4172$.

(78) Rao, Q.; Leng, Y. Effect of Layer Charge on $\mathrm{CO}_{2}$ and $\mathrm{H}_{2} \mathrm{O}$ Intercalations in Swelling Clays. Langmuir 2016, 32 (44), 11366-11374.

(79) Liu, P.; Harder, E.; Berne, B. J. On the Calculation of Diffusion Coefficients in Confined Fluids and Interfaces with an Application to the Liquid-Vapor Interface of Water. J. Phys. Chem. B 2004, 108, 65956602. 
Table 1: Charges $q$ and LJ parameters $\sigma$ and $\varepsilon$ of water, clay, and ion.

\begin{tabular}{lccr}
\hline Force or charge site & $\sigma(\AA)$ & $\varepsilon / k_{B}(\mathrm{~K})$ & $q(\mathrm{e})$ \\
\hline Water $(S P C)^{55,56}$ & 3.1656 & 78.2000 & -0.8200 \\
$\mathrm{O}$ & 0.0 & 0.0 & 0.4100 \\
$\mathrm{H}$ & & & \\
& & & \\
Montmorillonite (CLAYFF) & & & \\
Hydroxyl H & 0.0000 & 0.0000 & 0.4250 \\
Hydroxyl O & 3.1656 & 78.2000 & -0.9500 \\
Hydroxyl O with substitution & 3.1656 & 78.2000 & -1.0808 \\
Bridging O & 3.1656 & 78.2000 & -1.0500 \\
Bridging O with octahedral substitution & 3.1656 & 78.2000 & -1.1808 \\
Tetrahedral Si & 3.3020 & $9.2618 \times 10^{-4}$ & 2.1000 \\
Octahedral Al & 4.2712 & $6.6918 \times 10^{-4}$ & 1.5750 \\
Octahedral Mg & 5.2643 & $4.5440 \times 10^{-4}$ & 1.3600 \\
& & & \\
Ion & & & \\
Li $^{57}$ & & & \\
$\mathrm{Na}^{24,55}$ & 1.3723 & 9.2130 & 1.0000 \\
$\mathrm{~K}^{55,58}$ & 2.3500 & 65.5128 & 1.0000 \\
$\mathrm{Mg}^{57}$ & 3.3340 & 50.3584 & 1.0000 \\
$\mathrm{Ca}^{55,58}$ & 1.6444 & 440.6085 & 2.0000 \\
$\mathrm{Sr}^{57}$ & 2.8720 & 50.3584 & 2.0000 \\
\hline & 3.4620 & 50.3584 & 2.0000 \\
\hline
\end{tabular}


Table 2: Approximate RH ranges and the corresponding hydration states/basal $d$-spacings observed experimentally and employed in our simulations for Arizona montmorillonite in contact with water at $T=298.15 \mathrm{~K}$. The maximum deviation of the basal spacings obtained by swelling free-energy analysis/experiments from those used here was about $5 \%$.

\begin{tabular}{|c|c|c|c|}
\hline \multirow[t]{2}{*}{ Clay type } & \multirow[t]{2}{*}{$\mathrm{RH}(\%)$} & \multicolumn{2}{|c|}{ hydration state/basal $d$-spacing } \\
\hline & & Experiment $^{6,13}$ & Simulation $(\AA)$ \\
\hline \multirow{2}{*}{ Li-montmorillonite } & $0-50$ & $1 \mathrm{~W}$ & 12.0 \\
\hline & $50-100$ & $2 \mathrm{~W}$ & 15.0 \\
\hline \multirow{3}{*}{ Na-montmorillonite } & $0-10$ & 0W & 10.0 \\
\hline & $10-50$ & $1 \mathrm{~W}$ & 12.0 \\
\hline & $50-100$ & $2 \mathrm{~W}$ & 15.0 \\
\hline \multirow{2}{*}{$\overline{\mathrm{K} \text {-montmorillonite }}$} & $0-10$ & 0W & 10.0 \\
\hline & $10-100$ & $1 \mathrm{~W}$ & 12.0 \\
\hline \multirow{2}{*}{ Mg-montmorillonite } & $0-10$ & $1 \mathrm{~W}$ & 12.0 \\
\hline & $10-100$ & $2 \mathrm{~W}$ & 15.0 \\
\hline \multirow[t]{2}{*}{ Ca-montmorillonite } & $0-10$ & $1 \mathrm{~W}$ & 12.0 \\
\hline & $10-100$ & $2 \mathrm{~W}$ & 15.0 \\
\hline \multirow[t]{2}{*}{ Sr-montmorillonite } & $0-20$ & $1 W$ & 12.0 \\
\hline & $20-100$ & $2 W$ & 15.0 \\
\hline
\end{tabular}




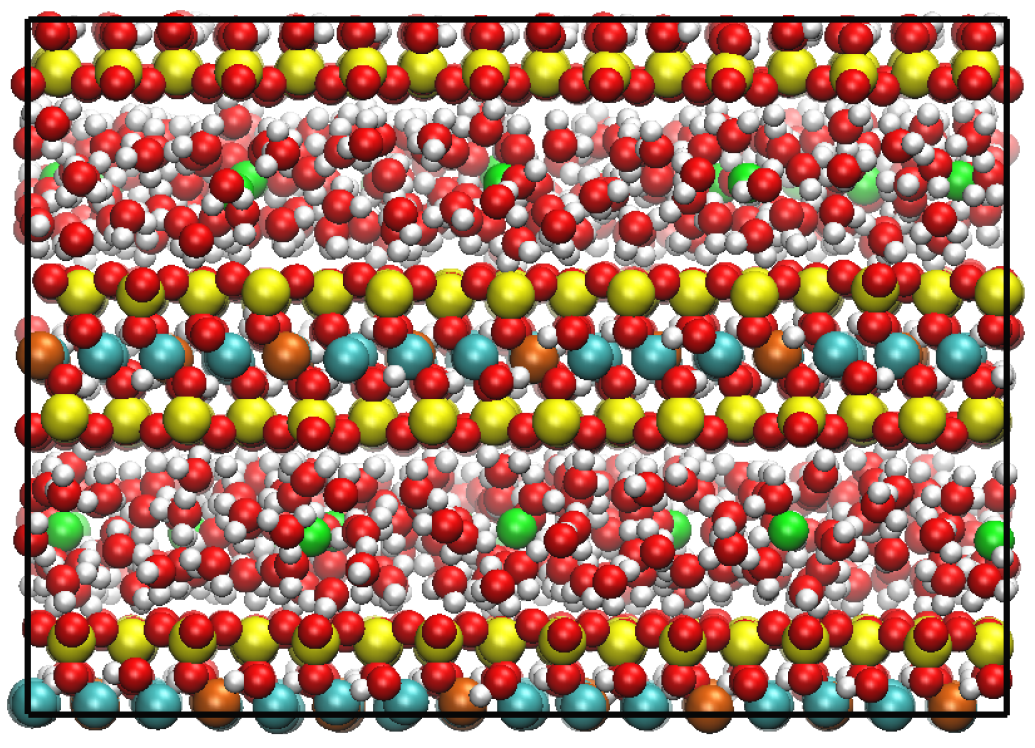

Figure 1: Equilibrium snapshot of Arizona Sr-montmorillonite in contact with water ( $\mathrm{RH}$ of $80 \%$ ) at $T=298.15 \mathrm{~K}$. Color code: O, red; H, white; Si, yellow; Al, cyan; Mg, orange; Sr, green. 
(a)

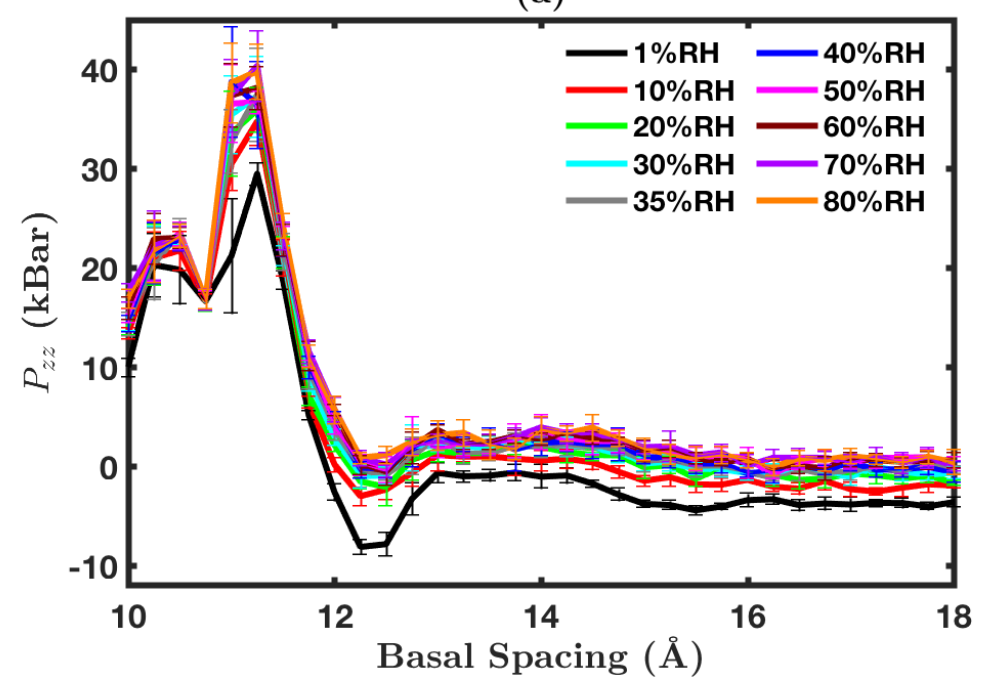

(b)

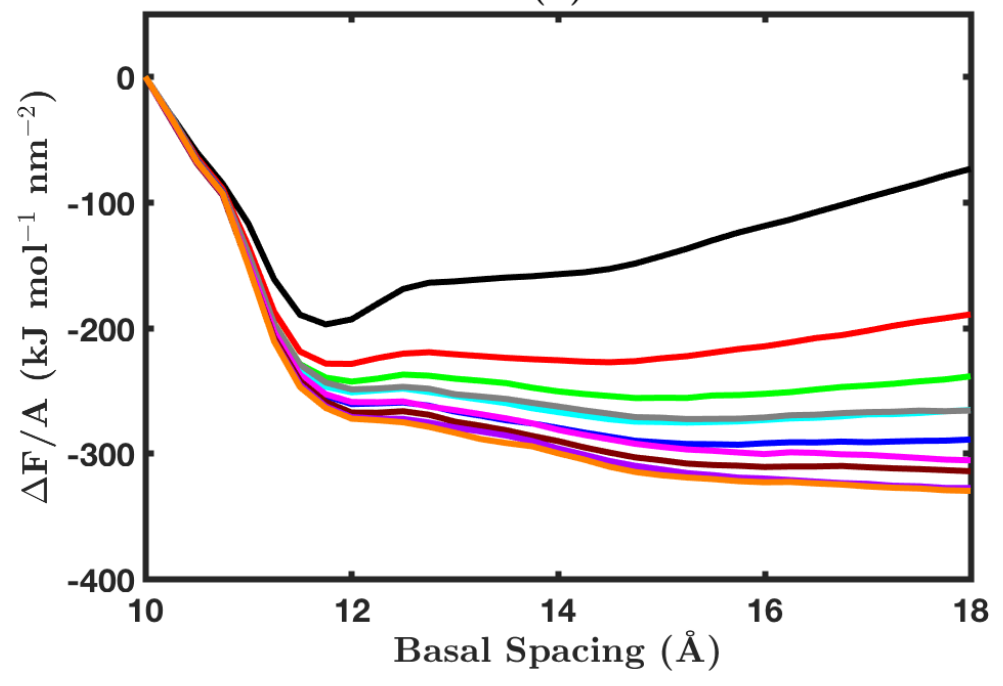

Figure 2: Variations of (a) normal pressure $P_{z z}$ and (b) swelling free energy per clay platelet area $\Delta F / A$ as a function of the basal $d$-spacing for Arizona Sr-montmorillonite at $T=298.15 \mathrm{~K}$. Simulations are performed under different RH conditions. 
(a)

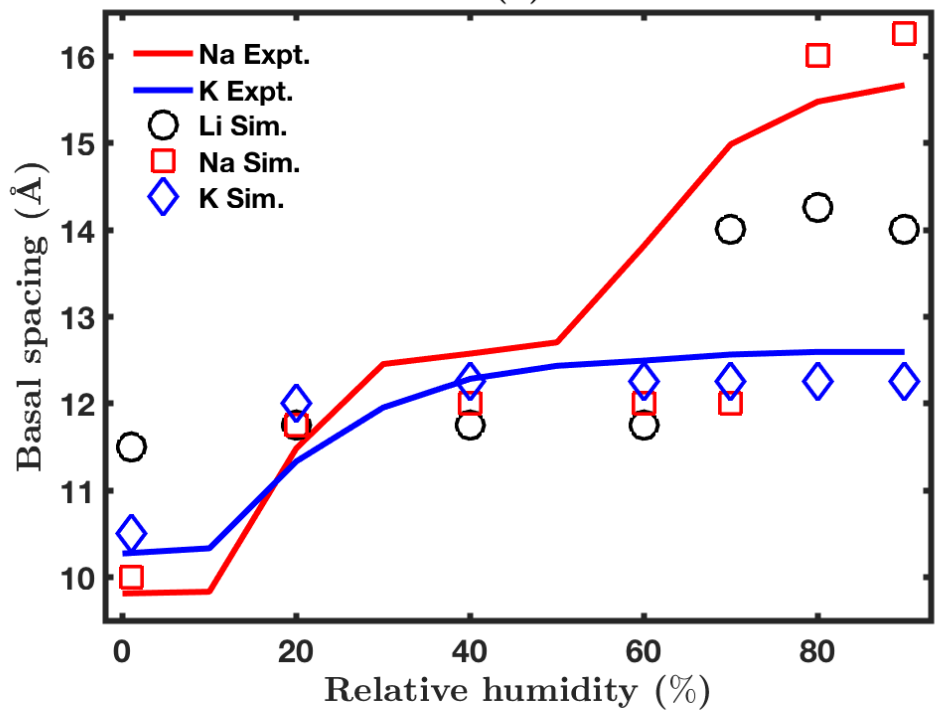

(b)

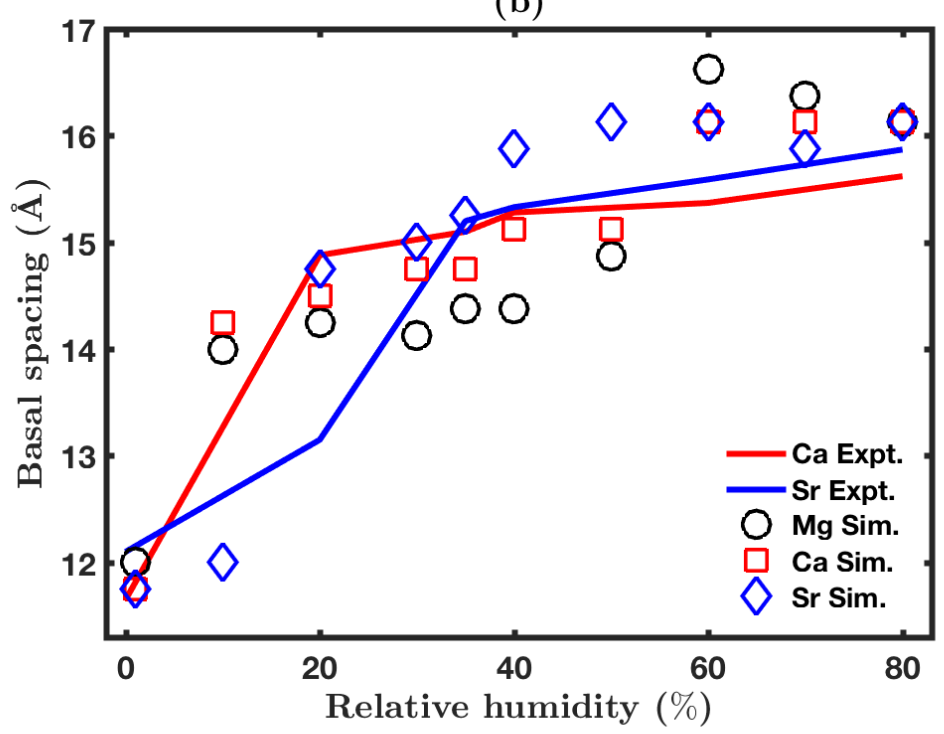

Figure 3: RH dependence of the basal $d$-spacing as computed from our GCMC simulations (symbols) and the corresponding experimental data ${ }^{6,13}$ (lines) for Arizona samples saturated with (a) monovalent and (b) divalent cations at $T=298.15 \mathrm{~K}$. In simulations, the maximum error was about $5 \%$. 
(a)

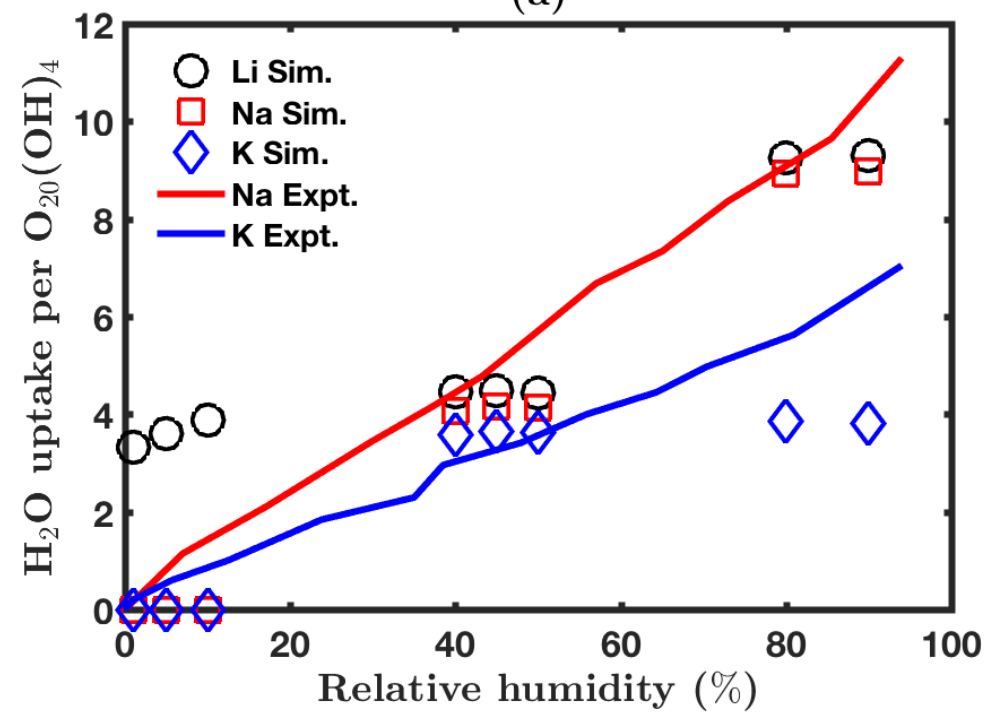

(b)

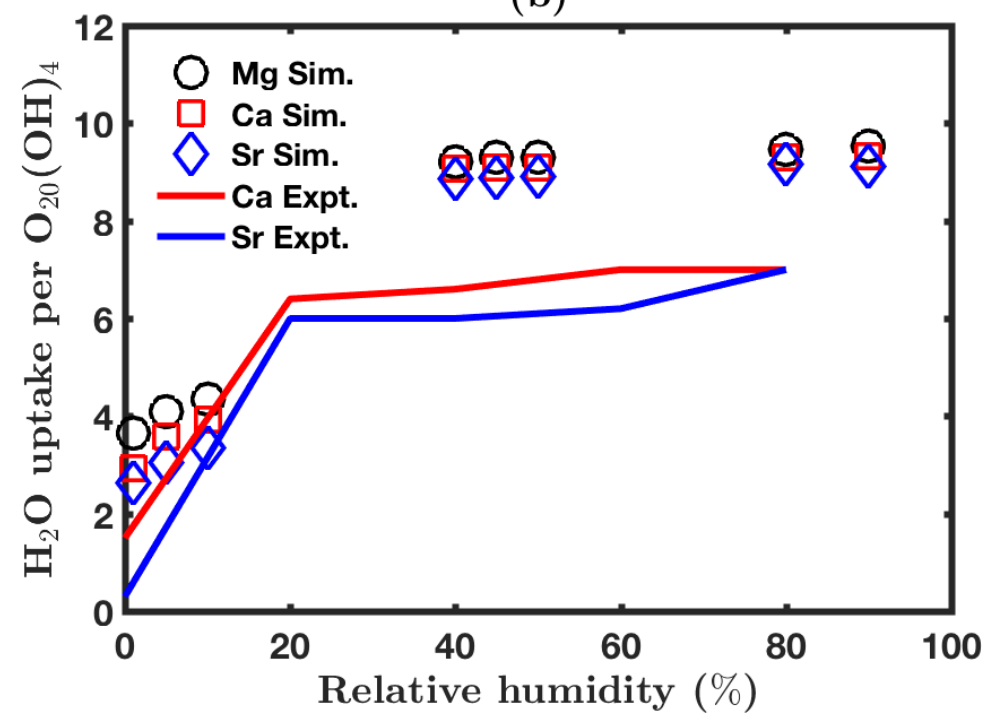

Figure 4: RH dependence of water uptake as computed from our GCMC simulations (symbols) and the corresponding experimental data ${ }^{9,13}$ for Arizona samples saturated with (a) monovalent and (b) divalent cations at $T=298.15 \mathrm{~K}$. Error bars are smaller than the symbol size. The basal $d$-spacings are as given in Table 2 . 
(a)

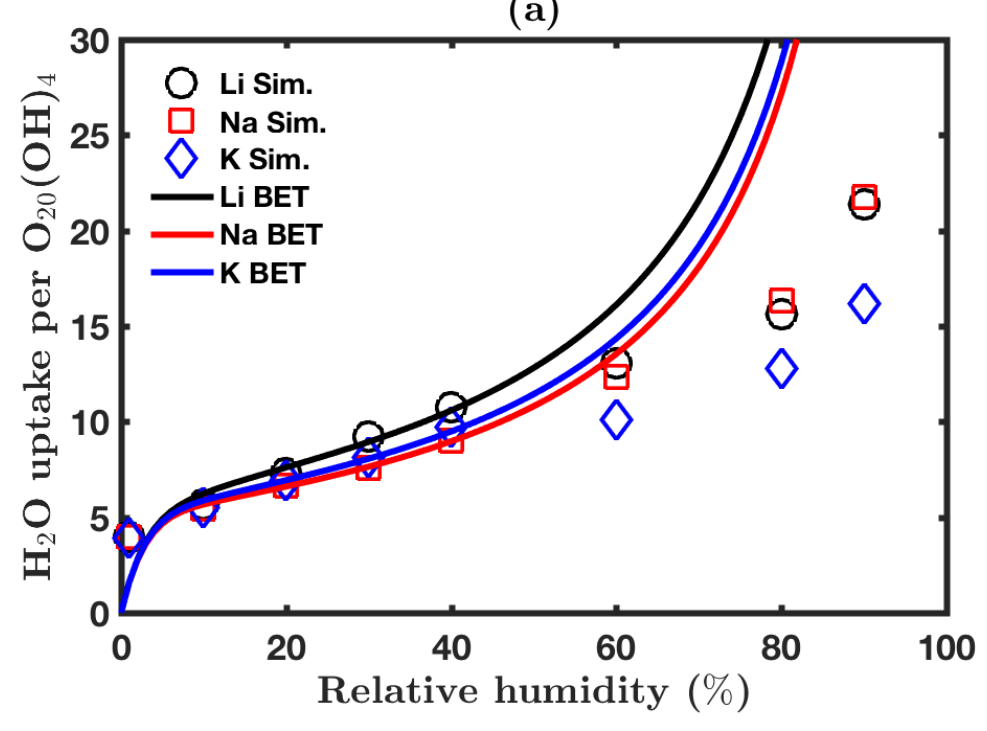

(b)

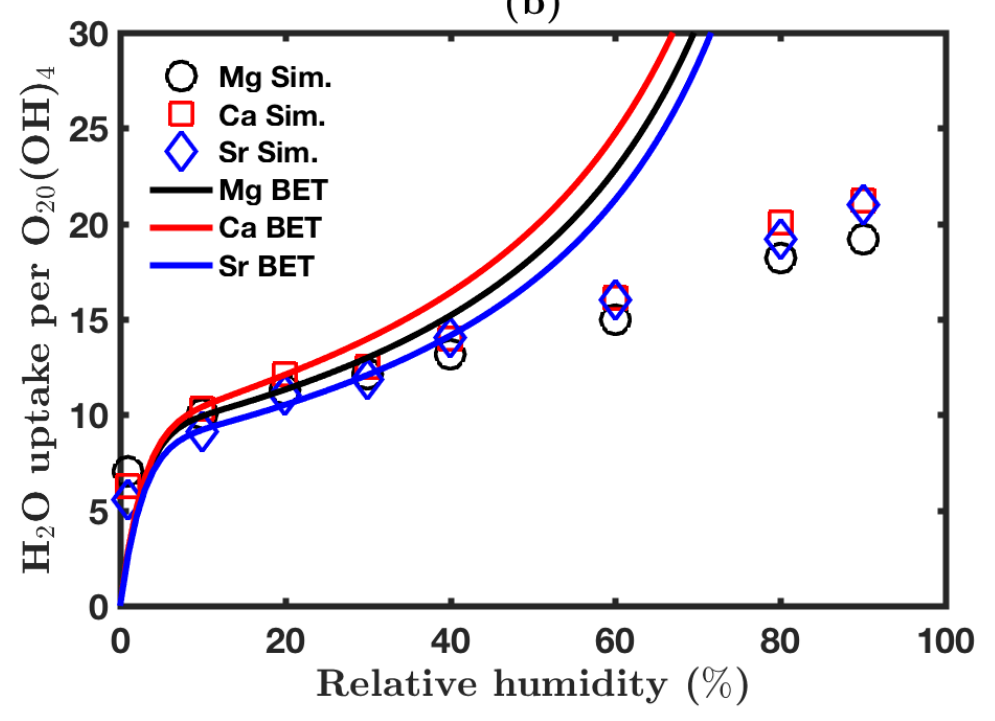

Figure 5: RH dependence of water uptake as computed from our GCMC simulations (symbols) and the corresponding BET model (lines) for Arizona samples saturated with (a) monovalent and (b) divalent cations at $T=298.15 \mathrm{~K}$. Error bars are smaller than the symbol size. The basal $d$-spacing is fixed at $65 \AA$. 
(a)

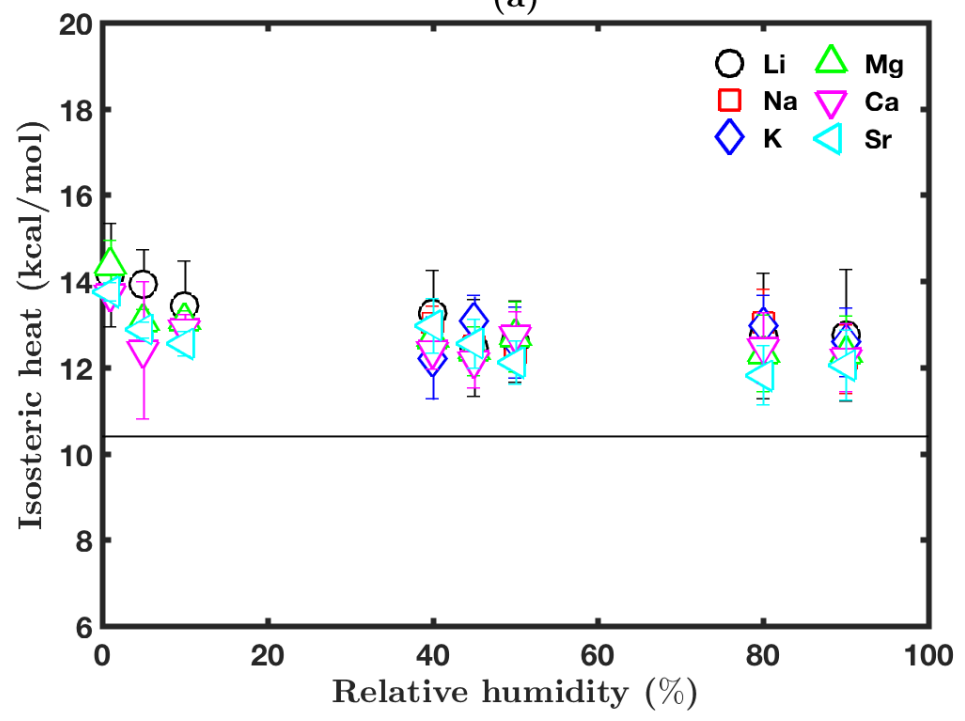

(b)

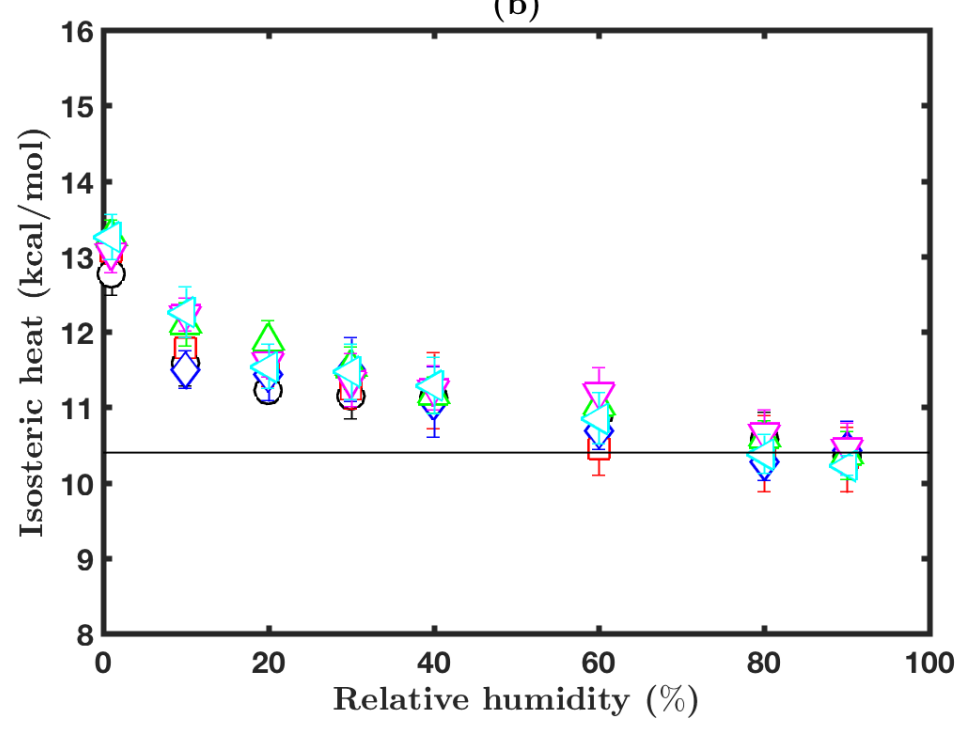

Figure 6: RH dependence of the isosteric heat of adsorption of water in (a) interlayers and on (b) external surfaces of the Arizona montmorillonite. The line represents the heat of vaporization of water. ${ }^{72}$ 
(a)

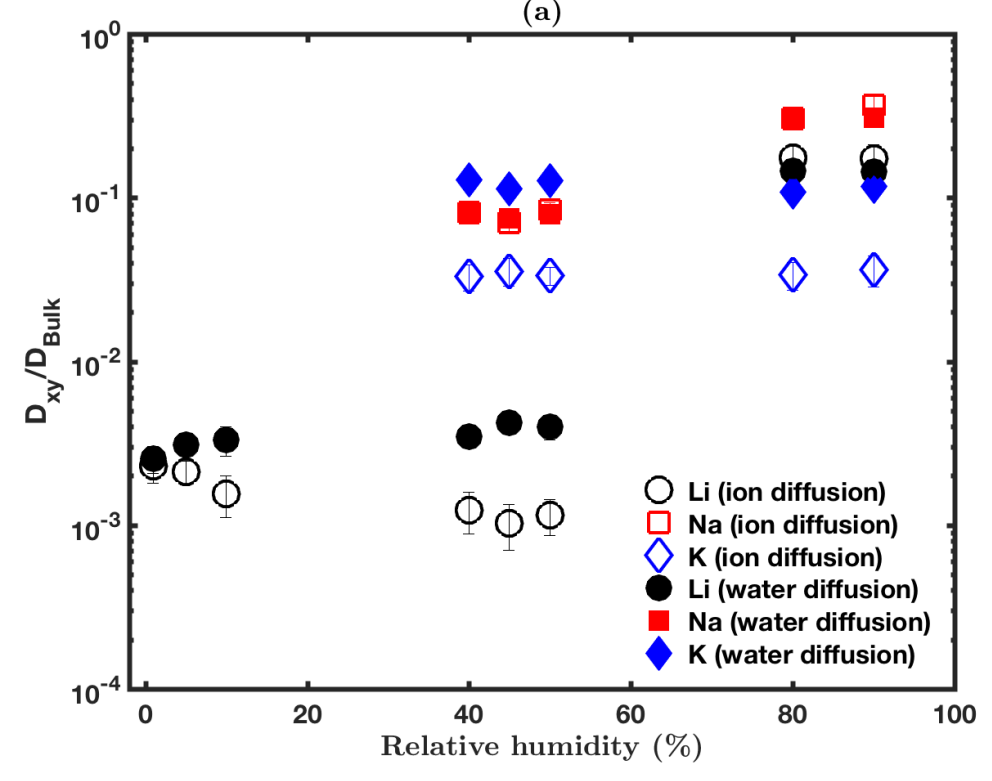

(b)

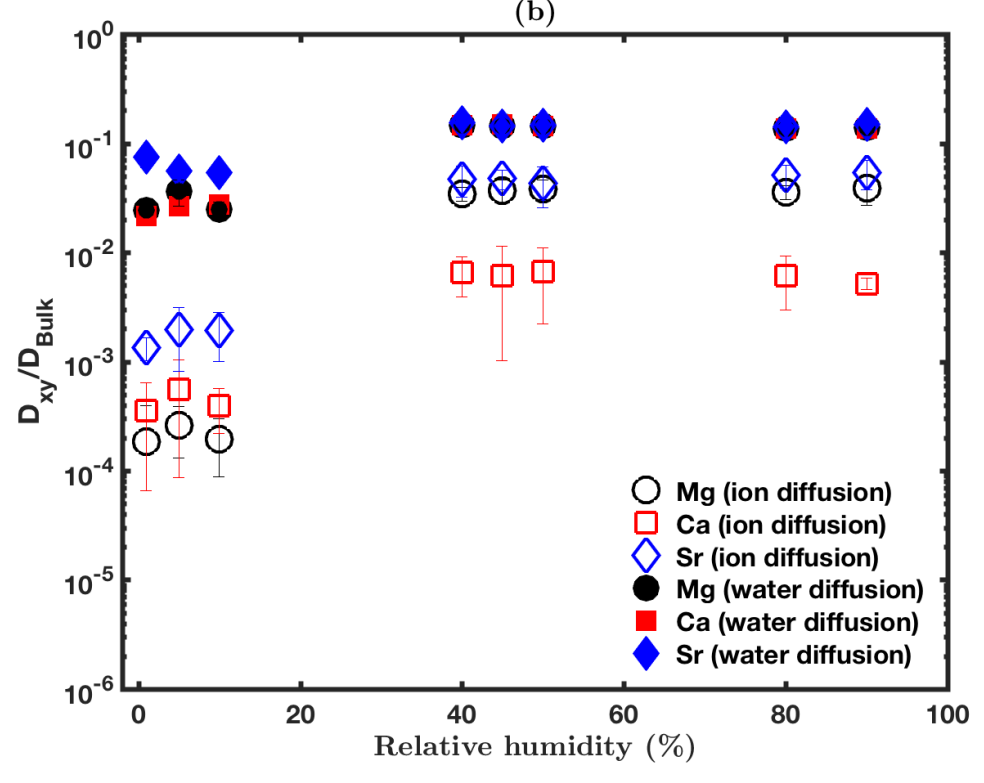

Figure 7: Normalized diffusion coefficients of interlayer ions (open symbols) and corresponding $\mathrm{H}_{2} \mathrm{O}$ (solid symbols) as a function of $\mathrm{RH}$ for Arizona samples saturated with (a) monovalent and (b) divalent cations at $T=298.15 \mathrm{~K}$. The basal $d$-spacings are as given in Table 2 . 
(a)

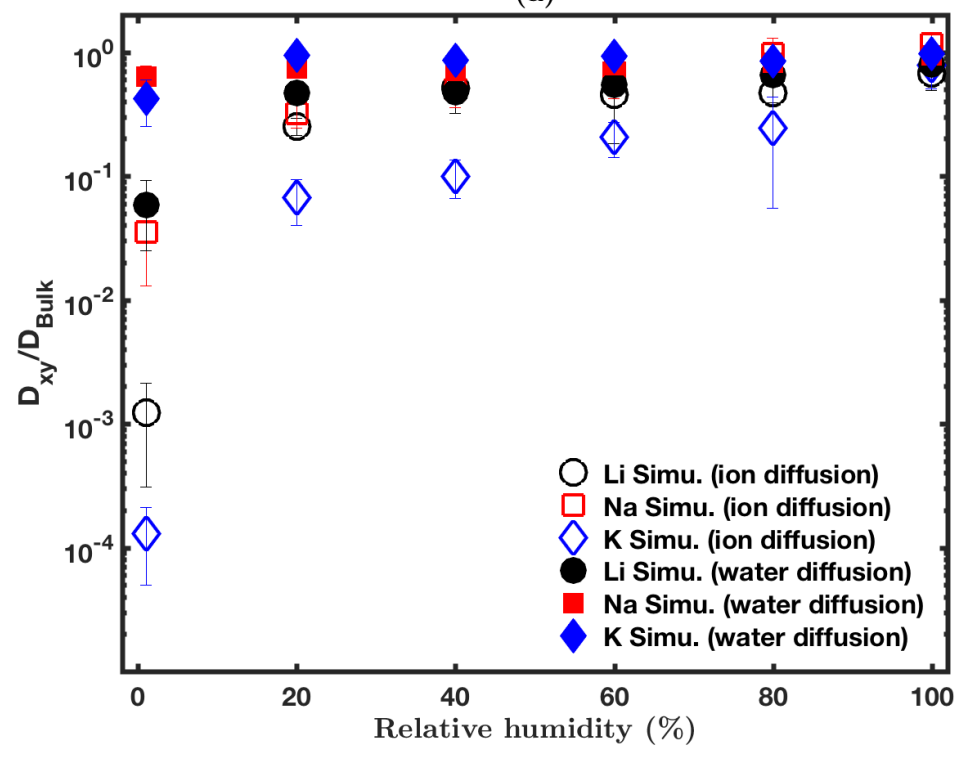

(b)

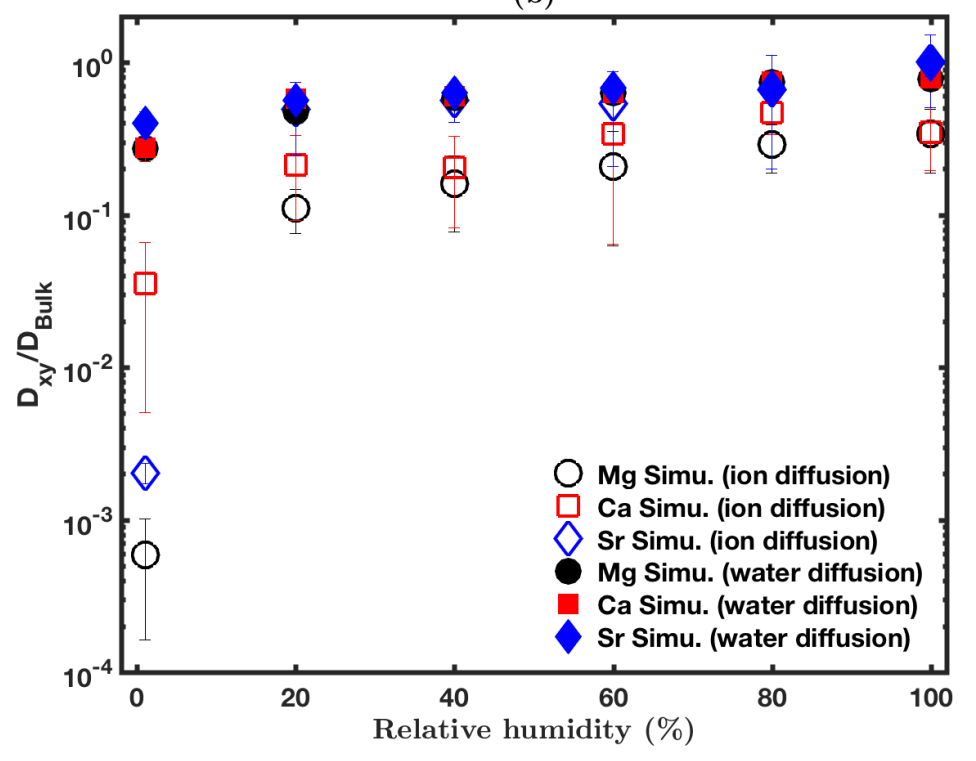

Figure 8: Normalized diffusion coefficients of ions (open symbols) and corresponding $\mathrm{H}_{2} \mathrm{O}$ (solid symbols) as a function of $\mathrm{RH}$ for Arizona samples saturated with (a) monovalent and (b) divalent cations at $T=298.15 \mathrm{~K}$. The basal $d$-spacing is fixed at 65 $\AA$. 
(a)

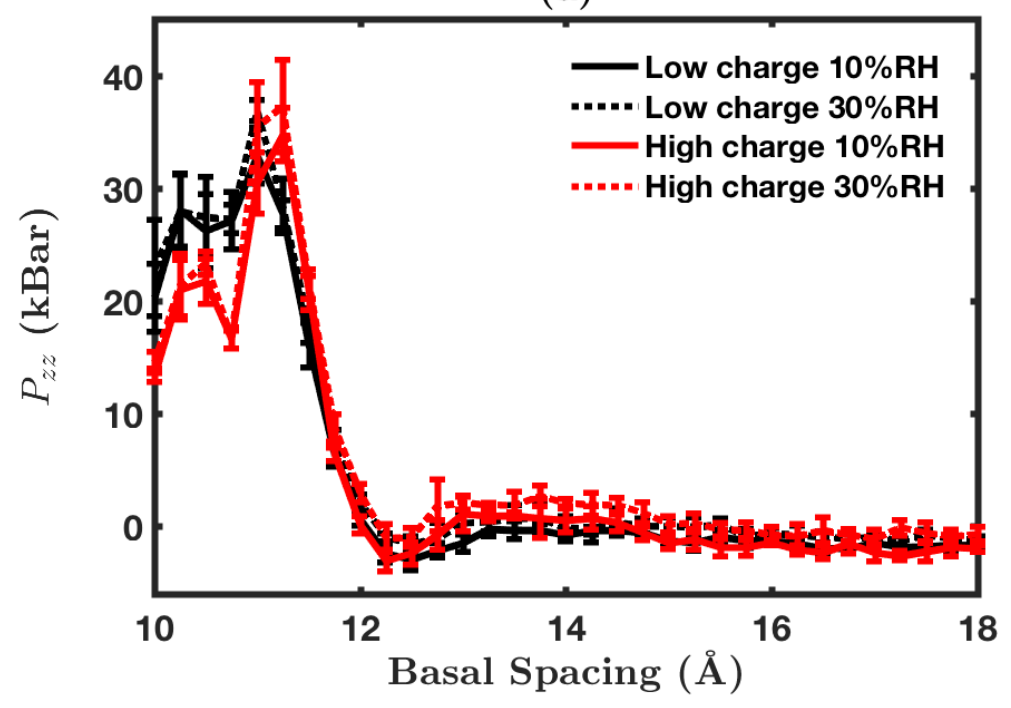

(b)

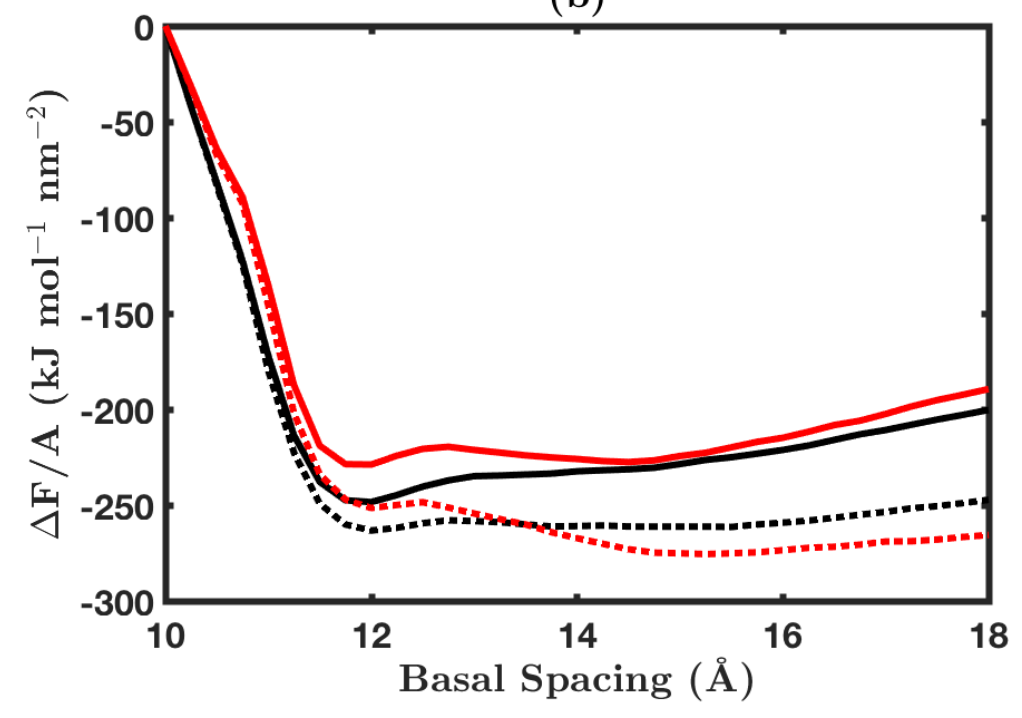

Figure 9: Variations of (a) normal pressure $P_{z z}$ and (b) swelling free energy per clay platelet area $\triangle F / A$ as a function of the basal $d$-spacing for low- and high-charge Sr-montmorillonite at $T=298.15 \mathrm{~K}$. 
Arizona Montmorillonite
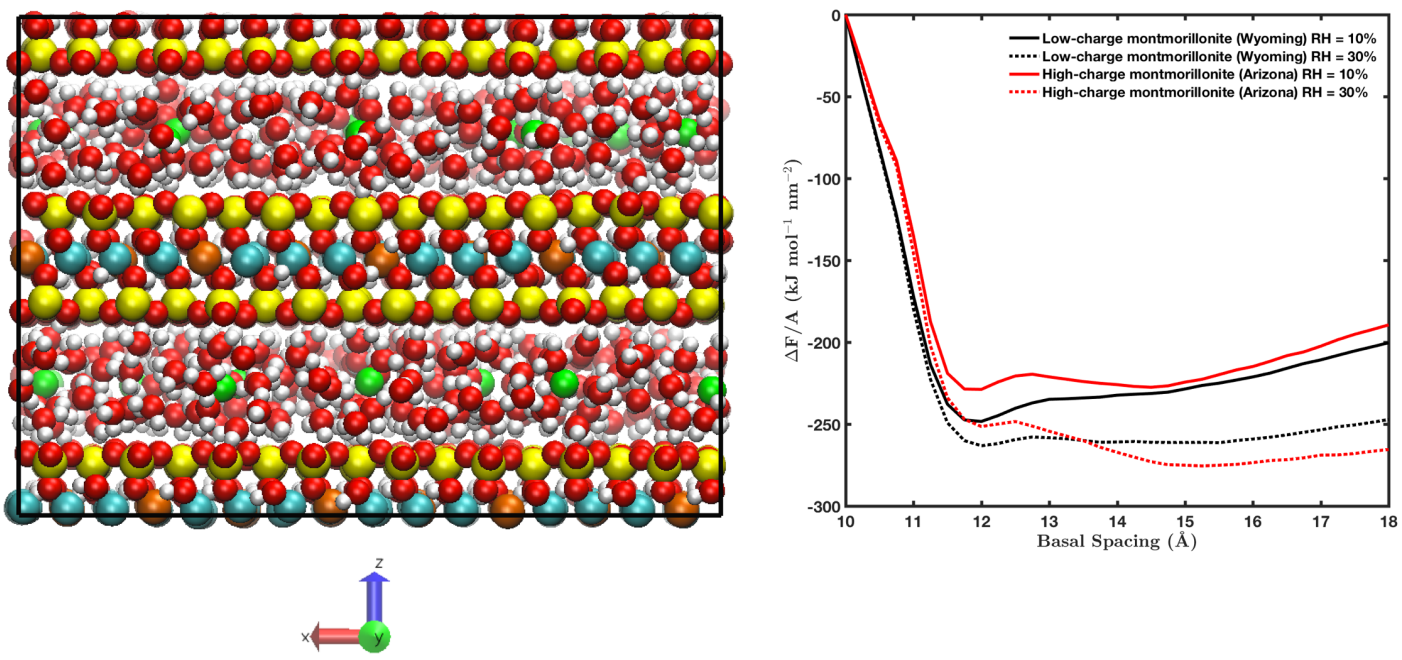

Table of Contents (TOC) Image 